\title{
XFM-guided delivery of imaging-visible human mesenchymal stem cells into the pericardial space in a porcine model
}

\author{
Yingli Fu ${ }^{1 *}$, Nicole Azene ${ }^{2}$, Tina Ehtiati ${ }^{3}$, Aaron Flammang ${ }^{3}$, Jens Guehring ${ }^{4}$, Wesley Gilson ${ }^{3}$, Judy A Cook ${ }^{1}$, \\ Clifford R Weiss ${ }^{1}$, Peter $V$ Johnston ${ }^{5}$, Dara Kraitchman ${ }^{1,2}$
}

From 15th Annual SCMR Scientific Sessions

Orlando, FL, USA. 2-5 February 2012

\section{Background}

Transmyocardial delivery of stem cells in the setting of acute myocardial ischemia has shown promise to prevent adverse ventricular remodeling ${ }_{1}$. However, the efficacy is limited by poor cell retention and low survival rates, even for autologous cells. Intrapericardial delivery of microencapsulated stem cells may offer a local and minimally invasive route to enhance cell survival and retention. In this study, we assess the delivery of human mesenchymal stem cells (hMSCs) in a radiopaque microcapsule to the pericardium using $\mathrm{x}$-ray fused with magnetic resonance imaging (XFM) in a porcine model.

\section{Methods}

Stem cell microencapsulation was performed using a modification of the alginate microencapsulation method by the addition of $10 \%(w / v) ~ B a S O 4$ (BaCaps, Fig.1A) ${ }_{2}$. Female Yorkshire pigs $(\sim 25 \mathrm{~kg}, \mathrm{n}=7)$ were randomized to receive either empty BaCaps $(\sim 10 \mathrm{ml})$, naked hMSCs $\left(1 \times 10_{8}\right)$, saline, or BaCaps with hMSCs $\left(8 \times 10_{7}\right)$ using a percutaneous approach. Prior to delivery, cine breathheld short-axis images were acquired to determine ventricular function (Argus, Siemens). A navigator-gated 3D whole heart MRI (1.5T Espree, Siemens SSFP, TR/ $\mathrm{TE}=290 / 1.67 \mathrm{~ms}, \quad \mathrm{FOV}=320 \times 240 \mathrm{~mm}$, image matrix $=256 \times 173, \mathrm{iPAT}=2$, slice $=64$, slice thickness $=2$ $\mathrm{mm}$ ) was also obtained to define ventricular borders for intrapericardial injection. A cardiac-gated c-arm CT (dynaCT, Axiom Artis dFA, Siemens, $190^{\circ}$ rotation; $0.5^{\circ}$ angle; 20s acquisition; $48 \mathrm{~cm}$ FOV) was then obtained and fused with the whole heart MRI and overlaid on

${ }^{1}$ Radiology, Johns Hopkins University, Baltimore, MD, USA

Full list of author information is available at the end of the article live fluoroscopy to guide percutaneous access to the pericardial space. For chronic studies, MRI and c-arm CT imaging were repeated one week after injection. Animals were sacrificed immediately or one week postdelivery for histological analysis.

\section{Results}

The viability of Ba-encapsulated hMSCs was $94.8 \pm 6 \%$ two days after encapsulation (Fig.1B). Using XFM (Fig.1C), successful puncture and delivery of BaCaps or Ba-encapsulated hMSCs was achieved in all animals. BaCaps were detected on fluoroscopic and c-arm CT images immediately and one week after delivery (Fig.1D). Whereas BaCaps were free floating immediately after delivery, at one week the BaCaps had consolidated as a pseudo epicardial tissue patch. Cardiac function was maintained 1 week post-delivery (LVEF: $36.8 \pm 4 \%$ at baseline vs. $41.5 \pm 5 \%$ at 1 week, $n=5$ ). Pericardial adhesions and effusion were absent at one week.

\section{Conclusions}

XFM-guided intrapericardial injection of Ba-encapsulated hMSCs was safe and reliable. This approach holds promise for safe delivery of allogeneic cellular therapeutics to the heart in patients without pericardial effusion.

\section{Funding}

Funding was provided by grants: R21/R33-HL89029, MD-SCRFII-0399 and Siemens healthcare.

\footnotetext{
Author details

${ }^{1}$ Radiology, Johns Hopkins University, Baltimore, MD, USA. ${ }^{2}$ Molecular \&

Comparative Pathobiology, Johns Hopkins University, Baltimore, MD, USA.

${ }^{3}$ Siemens Corporate Research, Baltimore, MD, USA. ${ }^{4}$ Siemens Healthcare,
} 


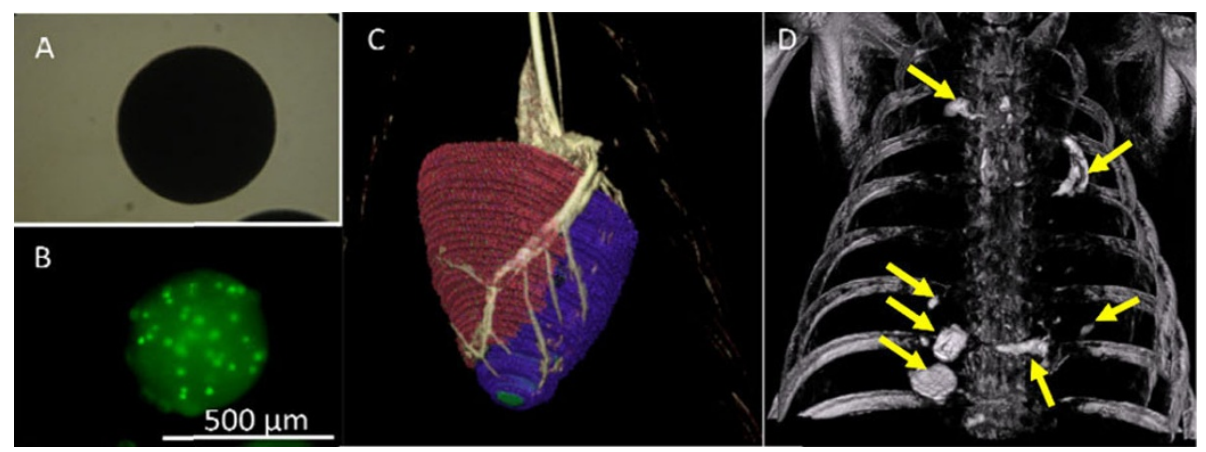

Figure 1 A) Microscopic view of BaCaps. B) Fluorescence image of Ba-encapsulated hMSCs demonstrating high cell viability (green) 2 days after encapsulation. C) XFM of the pig heart showing coronary vasculature (gray) and ventricular boundaries from MRI (colors). D) Cardiac-gated c-arm CT image showing the persistence of BaCaps in pericardial space one week post delivery (arrows).

Erlangen, Germany, USA. ${ }^{5}$ Medicine, Johns Hopkins University, Baltimore, MD, USA.

Published: 1 February 2012

doi:10.1186/1532-429X-14-S1-P63

Cite this article as: Fu et al: XFM-guided delivery of imaging-visible

human mesenchymal stem cells into the pericardial space in a porcine model. Journal of Cardiovascular Magnetic Resonance 2012 14(Suppl 1):P63.

\section{Submit your next manuscript to BioMed Central} and take full advantage of:

- Convenient online submission

- Thorough peer review

- No space constraints or color figure charges

- Immediate publication on acceptance

- Inclusion in PubMed, CAS, Scopus and Google Scholar

- Research which is freely available for redistribution

Submit your manuscript at www.biomedcentral.com/submit 